\title{
Screening for genital tuberculosis in a limited resource country: case report
}

Sadie Namani ${ }^{1,3^{*}}$ (D, Emine Qehaja-Buçaj ${ }^{1}$ and Diellëza Namani ${ }^{2}$

\begin{abstract}
Background: Screening for benign or malignant process of pelvis in young females is a challenge for a physician in a limited resource country. Tuberculosis should be always considered in the differential diagnosis of a pelvic mass in countries with high prevalence of tuberculosis. Negative results of analysis of peritoneal fluid for acid-fast staining, late cultures, and unavailability of new diagnostics methods such as polymerase chain reaction and adenosine deaminase of the aspirated fluid from peritoneal cavity can often result in invasive diagnostic procedures such as laparotomy.

Case presentation: We report a case of a 24 year old Albanian unemployed female living in urban place in Kosovo who presented with abdominal pain, loss of appetite, fever, headache, a weight loss, nonproductive cough and menstrual irregularity for three weeks. In this example case, the patient with cystic mass in tubo-ovarial complex and elevated serum cancer antigen 125 levels was diagnosed for genital tuberculosis after performing laparotomy. Caseose mass found in left tubo-ovarial complex and histopathological examination of biopsied tissue were the fastest diagnostic tools for confirming pelvis TB. The Lowenstein-Jensen cultures were positive after six weeks and her family history was positive for tuberculosis.

Conclusion: Young females with abdominopelvic mass, ascites, a positive family history for tuberculosis and high serum cancer antigen 125, should always raise suspicion of tuberculosis especially in a limited resource country. A laparoscopy combined with peritoneal biopsy should be performed to confirm the diagnosis as this could lead to a prevention of unnecessary laparotomies.
\end{abstract}

Keywords: Genital tuberculosis, CA-125, Developing countries, Kosovo

\section{Background}

The incidence of genital tuberculosis (TB) is low and often attacks middle-aged females. However, it is a frequent cause of chronic pelvic inflammatory disease (PID) and infertility in other parts of the world [1]. TB should be always considered in the differential diagnosis of a pelvic mass among immigrants from developing countries, especially those from Asia, the Middle East and Latin America, as well as the human immunodeficiency virus (HIV) positive patients [2]. The most common primary location of genital TB is in Fallopian tubes. The cancer antigen 125 (CA-125) marker is sensitive

\footnotetext{
*Correspondence: sadie_namani@yahoo.com

${ }^{1}$ Clinic of Infectious Diseases, University Clinical Center of Kosovo, Prishtinë, Kosovo

${ }^{3}$ Medical Faculty, University of Prishtina, Kongresi i Manastirit 3A, Prishtinë, Kosovo

Full list of author information is available at the end of the article
}

when used for monitoring the progress of an established tumor [3]. Elevated serum CA-125 is not specific to ovarian cancer, however, and a positive result can, at times, be misleading [2]. In this case report, the elevated serum CA-125, 40 times higher from normal value, was associated with the upper tract genital TB.

\section{Case presentation}

A 24-year-old female patient woman was admitted to our hospital complaining of abdominal pain, loss of appetite, fever, headache, a weight loss, nonproductive cough and menstrual irregularity. Her symptoms started three weeks earlier and she was treated with antibiotics and steroids for Erythema nodosa and Polyarthritis. She had a positive family history for tuberculosis since her father had died two years ago from Pulmonary TB.

At admission, the patient was febrile, intoxicated, hypotensive, anemic, no palpable lymph nodes were 
noted, normal heart sounds, lungs with rales bilaterally, blood pressure was $90 / 60 \mathrm{mmHg}$, respirations $24 / \mathrm{min}$, Pulse 80 beats/min, enlarged liver and spleen, with dolente tenderness in lower left abdominal quadrant, meningeal sings were negative and the rest of physical examinations were normal.

From laboratory analysis revealed elevated ESR $=40$, $\mathrm{HB}=8.7 \mathrm{~g} / \mathrm{dl}$, leucocytes $=5.2 \times 10^{9} / \mathrm{L}, \quad \mathrm{CRP}=48$, liver enzymes, urea, glucose and kreatinin in normal levels, total proteins $=64 \mathrm{~g} / \mathrm{L}$, albumins $=36 \mathrm{~g} / \mathrm{L}, \mathrm{LDH}=492 \mathrm{U} / \mathrm{L}, \mathrm{Fe}=$ $8.6 \mathrm{mmol} / \mathrm{L}$, blood cultures sterile, Wright negative, Widal negative. Chest $\mathrm{x}$ rays bilateral adenitis as shown in Fig.1, Mantoux probe $15 \mathrm{~mm}$, HIV negative, serum CA $125=$ 1430...1455, CA 19-9, AFP, CEA and CA 15-3 in normal levels. Ultrasound and MRI of abdomen revealed cystic formation on left tubo-ovarial complex and ascites as shown in Figs. 2 and 3.

Abdominal paracentesis was performed and revealed clear exudative fluid with benign cells. In consultation with gynecologist, the patient underwent operation, suprapubic transversal laparotomy. During operation, in the left tubo-ovarial complex was found caseose mass which was sent together with samples from omentum, peritoneum and ascites for histopathology and microbiological examination. On histopathological examination were seen epiteloidal granulomas with gigantic multinuclear cells, lymphocyte infiltrations and caseous necrosis. On Lowenstein-Jensen cultures was isolated Mycobacterium tuberculosis sensitive to Rifampicin (RIF), Izoniazid (INH), Ethambutol (ETH) and Streptomycin (STM). The patient was treated with a 4-drug TB treatment regimen consisting of RIF, INZ, Pyrazinamide, and ETH

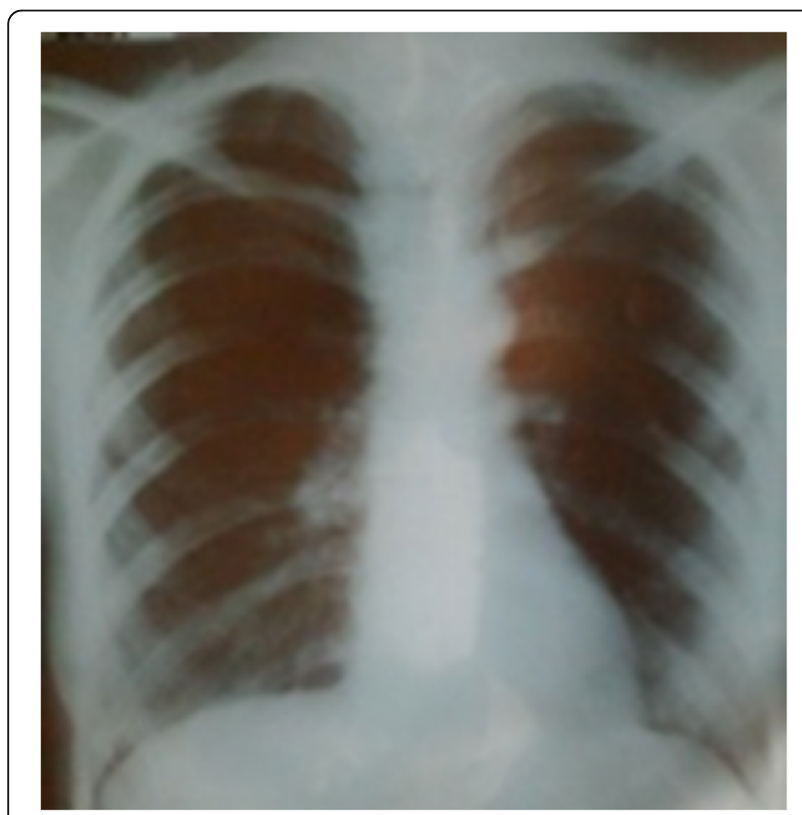

Fig. 1 Chest $X$ ray Adenitis hilly bill

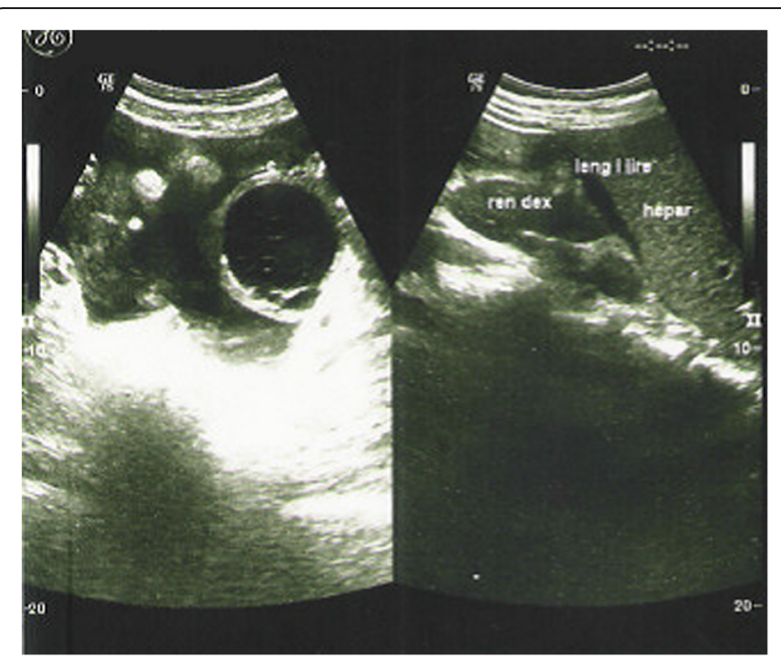

Fig. 2 Abdominal ultrasound: cystic formation in left tubo-ovarial complex and ascites

for the first two months and with two antituberculotics (RIF and INH) for another 7 months and recovered completely. Her serum cancer antigen 125 level was elevated for three months.

\section{Discussion}

Extrapulmonary tuberculosis is rarely seen at our Infectious Diseases Clinic in Prishtina, with less than $1 \%$ (20 cases or $0.6 \%$ ) of the total 3156 patients hospitalized during 2014. Of the 20 cases treated for extrapulmonary tuberculosis 17 patients were treated for TB Meningitis, and single cases of TB lymphadenitis, TB peritonitis and TB of genital tract.

Abdominal TB, which may involve the genitourinary or gastrointestinal tract, peritoneum, lymph nodes or solid viscera, constitutes up to $12 \%$ of extrapulmonary $\mathrm{TB}$ and $1-3 \%$ of the total, and its nonspecific signs and symptoms may be similar to gastrointestinal (GI) or ovarian cancers [4]. Signs and symptoms of our patients were similar to those observed from previous reports [5-7]. Fever was the main symptom of our patient and it was the most common finding (73\%) in the series reported by Muneef et al. [6]. Also, weight loss, menstrual irregularity, ascites, pelvic mass and a positive family history of TB, young age and geographic location in developing countries with high incidence of TB should direct the clinician to the diagnosis of upper genital tract TB. Helpful can be a positive TB skin test which is reported in about a quarter of patients in most reports [7]. Presence of TB at other sites and a positive family history of TB may be helpful in suggesting the diagnosis, but this was reported to occur in somewhat less than $30 \%$ of patients [5].

Pelvic TB can be caused by reactivation of the organism (spread via blood stream, lymphatic system or direct from 


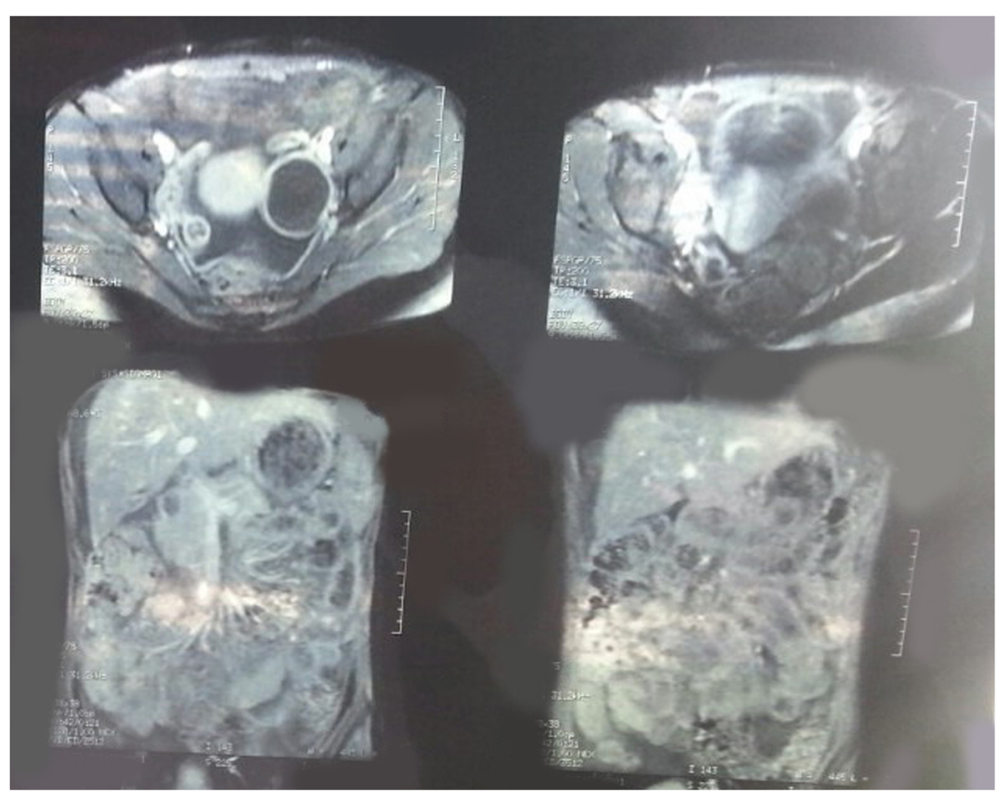

Fig. 3 Abdominal MRI: Cystic formation in left tubo-ovarial complex

the involved abdominal organs such as intestines) or rarely by venereal transmission [1]. Abdominal ultrasound and MRI of the pelvis was helpful for finding a cystic formation and directing us to suspect of a non-malignant disorder of the genital tract. Non-invasive methods such as tuberculin skin test, chest radiographs or acid-fast staining and culture of the aspirated fluid from peritoneal cavity are usually insufficient to provide the diagnosis of peritoneal or pelvic TB $[8,9]$. Abdominal paracentesis revealing clear exudative fluid with benign cells was not helpful, while polymerase chain reaction (PCR) of the aspirated fluid can't be done in developing countries such as ours. Some recently published studies argue that a positive PCR assay or high adenosine deaminase (ADA) level in aspirated fluid is diagnostic for TB [10, 11]. None of them can be done in our country.

Serum CA-125 is a specific marker for ovarian cancer but can be elevated in various conditions including peritoneal and pelvic TB, endometriosis, pelvic inflammatory disease, liver cirrhosis, chronic renal failure, pleural effusion and pancreas $[1,11-13]$. A value of $35 \mathrm{U} / \mathrm{mL}$ for CA-125 is considered the upper limit of normal [14]. In this case example, the level of serum CA-125 was 40 times higher from normal value. Cystic formation found by imaging, a positive TB skin test, a positive family history of tuberculosis, abdominal paracentesis were not helpful considering the high level of serum CA-125 found in this case which influenced the decision of the consultant gynecologist for laparotomy instead of laparoscopy. Caseose mass found in left tubo-ovarial complex by suprapubic transversal laparotomy and histopathological examination of biopsied tissue were the fastest diagnostic tools for confirming pelvis TB. The Lowenstein-Jensen cultures of the taken samples confirmed the suspected genital TB although 6 weeks later. For any suspicious mass of the upper genital tract, laparoscopy and histopathological examination of biopsied tissue should be the first intervention to prevent unnecessary surgery and starting appropriate and timely therapy.

\section{Conclusion}

Young females with abdominopelvic mass, ascites, and high serum cancer antigen 125, should always raise suspicion of tuberculosis especially in a limited resource country. A laparoscopy combined with peritoneal biopsy should be performed to confirm the diagnosis as this could lead to a prevention of unnecessary laparotomies.

\section{Abbreviations}

ADA: Adenosine deaminase; AFP: Alpha Fetoprotein; CA-125: Cancer antigen 125; CEA: Carcinoembryonic Antigen; CRP: C reactive protein;

ESR: Erythrocyte sedimentation rate; ETH: Ethambutol; Gl: Gastrointestinal; HB: Hemoglobin; HIV: human immunodeficiency virus; INH: Izoniazid;

LDH: Lactat dehydrogenase; MRI: Magnetic resonance imaging; PCR: Polymerase chain reaction; PID: Pelvic inflammatory disease; RIF: Rifampicin; STM: Streptomycin; TB: Tuberculosis

\section{Acknowledgements}

Staff of the Institute of Radiology of the University Clinical Center of Kosovo for their help in processing abdominal ultrasound and MRI images for publication.

\section{Funding}

The authors declare that they have no funding source.

Availability of data and materials Not applicable. 


\section{Authors' contributions}

All authors have read and approved the final manuscript. SN made primary contributions to the design of the study, data collecting, comparing the results with other publications and drafted manuscript. EQ-B contributed to the data collection and participated in additional correction and design.

DN scientific writer.

\section{Authors' information}

Not applicable.

\section{Competing interests}

The authors declare that they have no competing interests.

\section{Consent for publication}

Written informed consent was obtained from the patient for publication of this case report and any accompanying images. Also, a statement for ethical approval was obtained from ethical committee of Medical Faculty, University of Prishtina. A copy of the written consent from the patient and a statement for ethical approval is available for review by the Editor of this journal.

\section{Author details}

${ }^{1}$ Clinic of Infectious Diseases, University Clinical Center of Kosovo, Prishtinë, Kosovo. ${ }^{2}$ Smart Center, Prishtinë, Kosovo. ${ }^{3}$ Medical Faculty, University of Prishtina, Kongresi i Manastirit 3A, Prishtinë, Kosovo.

Received: 23 January 2016 Accepted: 1 February 2017

Published online: 07 February 2017

\section{References}

1. Hasanzadeh M, Naderi HR, Hoshyar AH, Shabane S, Shahidsales S. Female genital tract tuberculosis presenting as ovarian cancer. J Res Med Sci. 2014;19(2):184-9.

2. Rock J, Jones HW. Te Linde's operative gynecology, vol. 30. 10th ed. Philadelphia: Lippincott Williams and Wilkins; 2008. p. 677-8.

3. Carlson KJ, Skates SJ, Singer D. Screening for ovarian cancer. Ann Intern Med. 1994;121:124-32.

4. Sheer TA, Coyle WJ. Gastrointestinal tuberculosis. Curr Gastroenterol Rep. 2003;5:273-8.

5. Uzunkoy A, Harma M, Harma M. Diagnosis of abdominal tuberculosis: experience from 11 cases and review of the literature. World J Gastroenterol. 2004;10:3647-9.

6. Muneef MA, Memish Z, Mahmoud SA, Sadoon SA, Bannatyne R, Khan Y. Tuberculosis in the belly: a review of forty-six cases involving the gastrointestinal tract and peritoneum. Scand J Gastroenterol. 2001;36:528-32.

7. Demir K, Okten A, Kaymakoglu S, Dincer D, Besisik F, Cevikbas U, et al. Tuberculous peritonitis-reports of 26 cases, detailing diagnostic and therapeutic problems. Eur I Gastroenterol Hepatol. 2001:13:581-5.

8. Adali E, Dulger C, Kolusari A, Kurdoglu M, Yildizhan R. Pelvic-peritoneal tuberculosis simulating peritoneal carcinomatosis: high clinical suspicion and a minimally invasive procedure. Arch Gynecol Obstet. 2009;280:867-8.

9. Tinelli A, Malvasi A, Vergara D, Martignago R, Nicolardi G, Tinelli R, et al. Abdominopelvic tuberculosis in gynaecology: laparoscopical and new laboratory findings. Aust N Z J Obstet Gynaecol. 2008;48:90-5.

10. Tewari M, Sahoo SP, Shukla HS. Tuberculosis. In: Abdominal tuberculosis. 2nd ed. India: Jaypee Brothers Medical Publishers; 2009. p. 288.

11. Simsek H, Savas MC, Kadayifci A, Tatar G. Elevated serum CA 125 concentration in patients with tuberculosis peritonitis: a case-control study. Am J Gastroenterol. 1997:92:1174-6.

12. Thakur V, Mukherjee U, Kumar K. Elevated serum cancer antigen 125 levels in advanced abdominal tuberculosis. Med Oncol. 2001:18:289-91.

13. Bilgin T, Karabay A, Dolar E, Develioglu OH. Peritoneal tuberculosis with pelvic abdominal mass, ascites and elevated CA 125 mimicking ovarian carcinoma: a series of 10 cases. Int J Gynecol Cancer. 2001;11:290-4.

14. Finkler NJ. Clinical utility of CA 125 in preoperative diagnosis of patients with pelvic masses. Obstet Gynecol Reprod Biol. 1993;49(1-2):105-7.

\section{Submit your next manuscript to BioMed Central and we will help you at every step:}

- We accept pre-submission inquiries

- Our selector tool helps you to find the most relevant journal

- We provide round the clock customer support

- Convenient online submission

- Thorough peer review

- Inclusion in PubMed and all major indexing services

- Maximum visibility for your research

Submit your manuscript at www.biomedcentral.com/submit 